BMJ Open

Diabetes

Research

\& Care

\title{
Effect of alcohol consumption and the presence of fatty liver on the risk for incident type 2 diabetes: a population- based longitudinal study
}

\author{
Takuro Okamura (1) ," Yoshitaka Hashimoto (i) , ${ }^{1}$ Masahide Hamaguchi (D) ," \\ Akihiro Obora, ${ }^{2}$ Takao Kojima, ${ }^{2}$ Michiaki Fukui ${ }^{1}$
}

To cite: Okamura T, Hashimoto Y, Hamaguchi M, et al. Effect of alcohol consumption and the presence of fatty liver on the risk for incident type 2 diabetes: a population-based longitudinal study. BMJ Open Diab Res Care 2020;8:e001629. doi:10.1136/ bmjdrc-2020-001629

\section{- Additional material is published online only. To view, please visit the journal online (http://dx.doi.org/10.1136/ bmjdrc-2020-001629).}

Received 1 June 2020 Revised 28 July 2020 Accepted 4 August 2020
Check for updates

(c) Author(s) (or their employer(s)) 2020. Re-use permitted under CC BY-NC. No commercial re-use. See rights and permissions. Published by BMJ.

${ }^{1}$ Department of Endocrinology and Metabolism, Kyoto Prefectural University of Medicine, Kyoto, Japan ${ }^{2}$ Department of Gastroenterology, Asahi University Murakami Memorial Hospital, Gifu, Japan

Correspondence to Dr Masahide Hamaguchi; mhama@koto.kpu-m.ac.jp

\section{ABSTRACT}

Introduction Both fatty liver disease (FLD) and alcohol consumption have been reported to affect incident type 2 diabetes mellitus. The aim of this study was to evaluate the combined effect of FLD and alcohol consumption on incident type 2 diabetes.

Research design and methods In this historical cohort study involving 9948 men, we investigated the influence of the presence of FLD and the grades of alcohol consumption on incident type 2 diabetes using Cox proportional hazards models. We categorized the participants into the following four groups: none or minimal alcohol consumption, $<40 \mathrm{~g} / \mathrm{week}$; light, 40-140 $\mathrm{g} /$ week; moderate, 140-280 g/week; or heavy alcohol consumption, $>280 \mathrm{~g} /$ week. FLD was diagnosed by abdominal ultrasonography.

Results During the median 6.0-year follow-up, 568 participants developed type 2 diabetes. Heavy alcohol consumers with FLD showed a higher risk for developing type 2 diabetes compared with the other groups. Moderate alcohol consumers without FLD had a significantly higher risk for developing incident type 2 diabetes, compared with none or minimal and light alcohol consumers without FLD. In contrast, there was no apparent difference in the risk for incident type 2 diabetes between none or minimal, light, and moderate alcohol consumers with FLD. Furthermore, there was no statistically significant difference in the risk for incident type 2 diabetes between a moderate and heavy alcohol consumer without FLD and a none or minimal, light, and moderate alcohol consumer with FLD. Conclusions To prevent incident type 2 diabetes, we should acknowledge that the impact of alcohol consumption may vary in the presence of FLD.

\section{INTRODUCTION}

The cases of type 2 diabetes mellitus in Japan have been increasing after World War II. ${ }^{12}$ The estimated annual healthcare for patients with diabetes mellitus cost $\$ 37$ billion in Japan in 2014, ranking the country seventh in the world for total cases. ${ }^{3}$ Hence, the prevention, as well as treatment of type 2 diabetes, is of importance. Ectopic fat is extra adipose tissue in locations which is not associated initially with adipose tissue storage. ${ }^{4}$ Furthermore,

\section{Significance of this study}

What is already known about this subject?

- Alcohol is the cause of type 2 diabetes and fatty liver disease (FLD), and there is a U-shaped correlation between alcohol consumption and diabetes risk.

What are the new findings?

- Moderate alcohol consumers without FLD were associated with a risk for incident type 2 diabetes compared with none or minimal, or light alcohol consumers with FLD.

- None or minimal and light alcohol consumers were associated with a low risk for incident type 2 diabetes in individuals without FLD, but not in individuals with FLD.

- The risk for incident type 2 diabetes in heavy alcohol consumers with FLD was the highest.

How might these results change the focus of research or clinical practice?

- For the prevention of incident type 2 diabetes, clinicians have to focus on the presence of FLD and the patient's alcohol consumption.

fatty liver disease (FLD), caused by insulin resistance, is known as one of the causes of ectopic fat accumulation. ${ }^{56}$ FLD is divided into two subtypes: alcoholic fatty liver disease (AFLD) and non-AFLD (NAFLD). We have previously reported that FLD is a significant risk factor for the development of incident type 2 diabetes. ${ }^{6}$

Alcohol is recognized as the cause of various diseases, including type 2 diabetes and FLD. There is a U-shaped correlation between alcohol consumption and diabetes risk. ${ }^{78}$ Moreover, several studies have revealed that light to moderate alcohol consumption has protective effects on the incidence of FLD. ${ }^{9-11}$ A recent study demonstrated that light to moderate alcohol consumption decreased the risks of incident type 2 diabetes 
in people without NAFLD; however, light to moderate alcohol consumption was associated with an increased risk for type 2 diabetes in patients with NAFLD. ${ }^{12}$ Therefore, there is a possibility that the effect of alcohol consumption on type 2 diabetes may vary depending on background factors such as FLD. However, no previous studies have investigated the combined effect of FLD and alcohol consumption on incident type 2 diabetes.

In this study, we assessed the effect of alcohol consumption on the risk for incident type 2 diabetes in individuals with or without FLD. The results of this study may lead to a better understanding of the effects of alcohol consumption and provide guidance on how best to counsel individuals regarding their alcohol consumption according to the individual's background, such as the presence of FLD.

\section{RESEARCH DESIGN AND METHODS}

\section{Study participants and study design}

To elucidate the combined effect of the presence of FLD and alcohol consumption on the risk for incident type 2 diabetes, we used the NAfld in the Gifu Area, Longitudinal Analysis database, which is a population-based longitudinal analysis of a medical examination program at Asahi University Hospital (Gifu, Japan). This medical program, termed a human dock in Japan, aims to improve the health of the Japanese population by detecting chronic diseases and their risk factors at an early stage. The center was founded in 1994 and evaluates more than 8000 individuals annually with a repeating rate of $60 \% .^{6}$ Owing to low alcohol consumption in female participants, we focused on male participants for this study. We included the data of male participants of the medical examination program at the Asahi University Hospital from 2004 to 2016 more than or equal to two times. Last follow-up of this study was 2016. We excluded participants with medication usage, viral hepatitis (positive of hepatitis B antigen and/or hepatitis C antibody), missing data of covariates, and type 2 diabetes at the baseline examination.

\section{Data collection and measurements}

A standardized questionnaire, filled out by the participants, was used to obtain the medical history and lifestyle factors of all participants, including smoking, alcohol habits, and physical activity. Smoking status was categorized into three groups: never smoker, never smoked cigarettes; ex-smoker, quit smoking before the baseline visit; or current smoker; continued smoking at the baseline visit. Alcohol consumption was assessed by asking the participants about the type and amount of alcohol consumption per week during the prior month and then estimating the mean ethanol intake per week. Alcohol consumption status was categorized into the following four groups: none or minimal alcohol consumption, $<40 \mathrm{~g}$ /week; light, 40-140 g/week; moderate, 140-280 $\mathrm{g} /$ week; or heavy alcohol consumption, $>280 \mathrm{~g} /$ week. $^{9}$
Physical activity was evaluated by asking the participants' recreational and sports activities. ${ }^{6}$ Regular exercisers were defined as participants who played any type of sports equal to or more than once a week regularly. ${ }^{13}$

Levels of several factors including fasting plasma glucose, hemoglobin Alc (HbAlc), triglycerides, total cholesterol, high-density lipoprotein cholesterol, aspartate aminotransferase, alanine transaminase (ALT), and gamma-glutamyltranspeptidase were measured using venous blood after an overnight fast. Finally, incident type 2 diabetes was defined as HbAlc $\geq 6.5 \%$, fasting plasma glucose $\geq 7 \mathrm{mmol} / \mathrm{L}^{14}$ or self-reported.

\section{Definition of fatty liver}

Abdominal ultrasonography was performed for diagnosing FLD. ${ }^{15}$ Trained technicians performed the examination, and then gastroenterologists checked the images and made a diagnosis of FLD without referring to other personal data of the participants. Of the four known criteria (hepatorenal echo contrast, liver brightness, deep attenuation, and vascular blurring), the participants with liver brightness and liver contrast were diagnosed with fatty liver. ${ }^{15}$

\section{Statistical analysis}

Analysis was performed using JMP V.13.0 software (SAS, Cary, NC, USA), with a $p$ value $<0.05$ as significant. Furthermore, model assumptions were performed with EZR (Saitama Medical Center, Jichi Medical University, Saitama, Japan) ${ }^{6}$ Continuous variables were expressed as mean (SD) and categorical variables were expressed as number (percentage).

We divided the participants into eight groups according to the presence of FLD and the four grades of alcohol consumption, and the differences between the groups were compared. Categorical variables were compared between the groups using Pearson's $\chi^{2}$ test, and continuous variables were compared using one-way analysis of variance and the Tukey's honestly significant difference test, respectively. In addition, we adopted Kaplan-Meier analysis for a graphical presentation of time to incident type 2 diabetes and the log-rank test to evaluate differences between the eight groups. We performed a Bonferroni correction and set a $\mathrm{p}$ value $<0.00179$ as statistically significant in the log-rank test. Since censored cases were present and the follow-up duration was inconsistent, we chose the Cox proportional hazards model and calculated the HR of the eight groups with adjusting for several potential confounders as covariants, that is, age, body mass index (BMI), waist circumference, smoking status, exercise, HbAlc, triglycerides and ALT levels at baseline examination. Additionally, we have performed the same analyses in two categories according to the baseline year, the former half (2004-2009) and the latter half (2010-2015). Proportional hazards could be assumed in all covariates (online supplemental table 1). 
Table 1 Characteristics of the participants

\begin{tabular}{|c|c|}
\hline$n$ & 9948 \\
\hline Age (years) & $44.6(9.1)$ \\
\hline Body weight (kg) & $67.6(10.0)$ \\
\hline BMI (kg/m²) & $23.2(3.0)$ \\
\hline Waist circumference (cm) & $80.9(8.0)$ \\
\hline Non-smoker & 3257 (32.5) \\
\hline Ex-smoker & 3045 (30.7) \\
\hline Current smoker & $3646(36.8)$ \\
\hline Regular exerciser & $1862(18.8)$ \\
\hline $\begin{array}{l}\text { Alcohol consumption (g/ } \\
\text { week) }\end{array}$ & $100.4(159.2)$ \\
\hline $\begin{array}{l}\text { None or minimal alcohol } \\
\text { consumer }\end{array}$ & $5981(59.8)$ \\
\hline Light alcohol consumer & $1520(15.4)$ \\
\hline Moderate alcohol consumer & $1349(13.7)$ \\
\hline Heavy alcohol consumer & $1098(11.1)$ \\
\hline $\begin{array}{l}\text { Fasting plasma glucose } \\
(\mathrm{mmol} / \mathrm{L})\end{array}$ & $5.4(0.5)$ \\
\hline $\mathrm{HbA1c}(\mathrm{mmol} / \mathrm{mol})$ & $33.2(3.8)$ \\
\hline Triglycerides (mmol/L) & $1.2(0.8)$ \\
\hline Total cholesterol (mmol/L) & $5.2(0.9)$ \\
\hline HDL cholesterol (mmol/L) & $1.3(0.4)$ \\
\hline AST (IU/L) & $20.2(9.7)$ \\
\hline ALT (IU/L) & $24.7(15.2)$ \\
\hline GGT (IU/L) & $28.1(27.5)$ \\
\hline $\mathrm{SBP}(\mathrm{mm} \mathrm{Hg})$ & $119.6(14.4)$ \\
\hline DBP (mm Hg) & $75.5(10.1)$ \\
\hline Fatty liver & $2857(28.7)$ \\
\hline
\end{tabular}

Data are expressed as number (\%) of subjects or mean (SD). ALT, alanine aminotransferase; AST, aspartate aminotransferase; BMI, body mass index; DBP, diastolic blood pressure; GGT, gamma-glutamyltransferase; HbA1c, hemoglobin A1c; HDL, highdensity lipoprotein; SBP, systolic blood pressure.

\section{RESULTS}

We enrolled 20944 participants (12 498 men and 8446 women) (online supplemental figure 1). As previously stated, all female participants were excluded from this study. Next, 105 participants were excluded owing to missing data of covariates, including alcohol consumption and abdominal ultrasonography. Another 157 participants were excluded because they were detected with hepatitis B or $\mathrm{C}$ virus antibodies at baseline examination, and 1423 participants were excluded because they were taking medication at baseline examination. The 845 participants who had type 2 diabetes at baseline were also excluded. Thus, a total of 9948 participants were included in this study.

The baseline characteristics of the participants are summarized in tables 1 and 2 .
The proportions of none or minimal, light, moderate, and heavy alcohol consumers were $59.8 \%$ (5981), $15.4 \%$ (1520), 13.7\% (1349), and 11.1\% (1098), respectively. We investigated the differences in baseline characteristics between eight groups according to the presence or absence of FLD and grades of alcohol consumption. The proportions (number) of none or minimal, light, moderate and heavy alcohol consumers without FLD were $40.5 \%$ (3994), $12.1 \%$ (1189), $10.5 \%$ (1040) and $8.3 \%$ (821), respectively, and that of none or minimal, light, moderate, and heavy alcohol consumers with FLD were $19.3 \%$ (1903), 3.4\% (331), 3.1\% (309), and $2.8 \%$ (277), respectively. The participants with FLD were significantly more obese than those without. Furthermore, the waist circumference of those with FLD was significantly larger than those without FLD. Fasting plasma glucose levels were higher in the order of none or minimal, light, moderate, and heavy alcohol consumer both with and without FLD, whereas HbAlc was lower (table 2 and online supplemental table 2).

During the median 6.0-year follow-up, 568 participants developed type 2 diabetes. The 4000 days' cumulative incidence rates of type 2 diabetes in none or minimal, light, moderate, and heavy alcohol consumers without FLD were $2.3 \%, 2.7 \%, 4.2 \%$, and $5.7 \%$, respectively. Logrank tests were used to determine the association among the eight groups according to the presence or absence of FLD and grades of alcohol consumption (figure 1). Compared with none or minimal alcohol consumer without FLD, moderate alcohol consumer without FLD, heavy alcohol consumer without FLD, none or minimal alcohol consumer with FLD, light alcohol consumer with FLD, moderate alcohol consumer with FLD and heavy alcohol consumer with FLD were associated with higher risk of incident diabetes (all p<0.001). Compared with light alcohol consumer without FLD, heavy alcohol consumer without FLD, none or minimal alcohol consumer with FLD, light alcohol consumer with FLD, moderate alcohol consumer with FLD and heavy alcohol consumer with FLD were associated with higher risk of incident diabetes (all $\mathrm{p}<0.001)$. Compared with moderate alcohol consumer without FLD, none or minimal alcohol consumer with FLD, light alcohol consumer with FLD, moderate alcohol consumer with FLD and heavy alcohol consumer with FLD were associated with higher risk of incident diabetes $($ all $\mathrm{p}<0.001)$. The risks of incident of diabetes were not different among the FLD.

Compared with none or minimal alcohol consumers, light and moderate alcohol consumers did not show a significant risk for incident type 2 diabetes (light; HR $1.06,95 \%$ CI 0.82 to $1.36, \mathrm{p}=0.636$, moderate; HR 1.23 , $95 \%$ CI 0.95 to $1.59, \mathrm{p}=0.121)$, whereas heavy alcohol consumers showed a significant risk (HR 1.83, 95\% CI 1.49 to $2.26, \mathrm{p}<0.001)$. FLD also showed a significant risk (HR $1.83,95 \%$ CI 1.49 to $2.26, \mathrm{p}<0.001$ ) (table 3 ).

Figure 2 shows the results of HRs of the eight groups on incident type 2 diabetes. The groups of none or minimal without FLD and light alcohol consumers without 
Table 2 Characteristic of participants in the phenotype groups

\begin{tabular}{|c|c|c|c|c|}
\hline & None or minimal & Light & Moderate & Heavy \\
\hline \multicolumn{5}{|l|}{ FLD- } \\
\hline $\mathrm{n}$ & 3994 & 1189 & 1040 & 821 \\
\hline Age (years) & $43.2(9.3)$ & $45.1(9.1)$ & $46.6(9.3)$ & $47.5(8.5)$ \\
\hline Body weight (kg) & $64.6(8.4)$ & $65.1(8.1)$ & $65.2(8.5)$ & $65.5(8.5)$ \\
\hline Body mass index $\left(\mathrm{kg} / \mathrm{m}^{2}\right)$ & $22.1(2.4)$ & $22.2(2.4)$ & $22.4(2.4)$ & $22.5(2.5)$ \\
\hline Waist circumference $(\mathrm{cm})$ & $77.8(6.8)$ & $78.7(6.6)$ & $79.4(7.0)$ & $80.1(6.9)$ \\
\hline Non-smoker & $1654(40.1)$ & $343(28.9)$ & $212(20.4)$ & $111(13.6)$ \\
\hline Ex-smoker & $1107(27.1)$ & $402(33.8)$ & $363(35.0)$ & $258(31.6)$ \\
\hline Current smoker & $1336(32.8)$ & $443(37.3)$ & $462(44.6)$ & $447(54.8)$ \\
\hline Regular exerciser & $772(19.2)$ & $272(23.0)$ & $228(22.0)$ & $170(20.8)$ \\
\hline Alcohol consumption (g/week) & $14.4(20.6)$ & $104.9(18.6)$ & $194.6(41.8)$ & $444.8(248.1)$ \\
\hline Fasting plasma glucose (mmol/L) & $5.3(0.4)$ & $5.3(0.4)$ & $5.4(0.5)$ & $5.4(0.5)$ \\
\hline Hemoglobin A1c (mmol/mol) & $32.9(3.4)$ & $32.6(3.6)$ & $32.5(3.6)$ & $32.1(3.8)$ \\
\hline Triglycerides (mmol/L) & $0.9(0.6)$ & $1.0(0.6)$ & $1.1(0.8)$ & $1.2(1.0)$ \\
\hline Total cholesterol (mmol/L) & $5.1(0.8)$ & $5.1(0.8)$ & $5.1(0.8)$ & $5.1(0.8)$ \\
\hline HDL cholesterol (mmol/L) & $1.3(0.3)$ & $1.4(0.4)$ & $1.5(0.4)$ & $1.5(0.4)$ \\
\hline AST (IU/L) & $18.3(7.5)$ & $18.2(5.8)$ & $19.5(6.9)$ & $21.8(17.9)$ \\
\hline ALT (IU/L) & $20.3(10.4)$ & $19.9(8.6)$ & $20.7(9.2)$ & $22.5(12.9)$ \\
\hline GGT (IU/L) & $20.2(16.0)$ & $25.4(20.3)$ & $31.3(32.0)$ & $42.1(39.1)$ \\
\hline $\mathrm{SBP}(\mathrm{mm} \mathrm{Hg})$ & $115.6(13.0)$ & $117.5(13.8)$ & $119.6(13.8)$ & $123.1(14.8)$ \\
\hline $\mathrm{DBP}(\mathrm{mm} \mathrm{Hg})$ & $72.4(9.2)$ & $74.2(9.3)$ & $75.9(9.9)$ & $78.7(10.0)$ \\
\hline \multicolumn{5}{|l|}{ FLD+ } \\
\hline $\mathrm{n}$ & 1903 & 331 & 309 & 277 \\
\hline Age (years) & $44.0(8.2)$ & $45.9(8.7)$ & $47.0(8.4)$ & $46.2(8.5)$ \\
\hline Body weight $(\mathrm{kg})$ & $74.6(10.7)$ & $74.7(10.6)$ & $73.9(9.1)$ & $74.4(10.8)$ \\
\hline Body mass index $\left(\mathrm{kg} / \mathrm{m}^{2}\right)$ & $25.6(3.1)$ & $25.6(3.0)$ & $25.3(2.4)$ & $25.2(3.0)$ \\
\hline Waist circumference $(\mathrm{cm})$ & $86.8(7.4)$ & $87.4(7.4)$ & $87.3(6.5)$ & $87.3(7.5)$ \\
\hline Non-smoker & $751(39.6)$ & $81(24.6)$ & $61(19.8)$ & $44(15.9)$ \\
\hline Ex-smoker & $551(29.1)$ & $131(39.8)$ & $130(42.2)$ & $103(37.3)$ \\
\hline Current smoker & $31.4(595)$ & $117(35.6)$ & $117(38.0)$ & $129(46.7)$ \\
\hline Regular exerciser & $273(14.4)$ & $52(15.8)$ & $44(14.4)$ & $51(18.4)$ \\
\hline Alcohol consumption (g/week) & $11.9(19.1)$ & $104.6(18.5)$ & $196.8(42.1)$ & $442.5(167.6)$ \\
\hline Fasting plasma glucose (mmol/L) & $5.5(0.5)$ & $5.6(0.5)$ & $5.6(0.5)$ & $5.7(0.5)$ \\
\hline Hemoglobin A1c (mmol/mol) & $34.8(3.8)$ & $34.2(4.2)$ & $34.1(4.0)$ & $33.9(3.9)$ \\
\hline Triglycerides (mmol/L) & $1.5(0.8)$ & $1.6(1.0)$ & $1.6(0.9)$ & $1.8(1.1)$ \\
\hline Total cholesterol (mmol/L) & $5.4(0.8)$ & $5.4(0.8)$ & $5.5(0.9)$ & $5.4(0.8)$ \\
\hline HDL cholesterol (mmol/L) & $1.1(0.2)$ & $1.2(0.3)$ & $1.2(0.3)$ & $1.3(0.3)$ \\
\hline AST (IU/L) & $23.3(10.0)$ & $23.3(9.4)$ & $23.3(9.3)$ & $27.0(13.7)$ \\
\hline ALT (IU/L) & $35.6(20.8)$ & 34.6 (18.9) & $32.4(17.6)$ & 33.5 (16.5) \\
\hline GGT (IU/L) & $29.5(21.6)$ & $38.3(29.0)$ & $42.0(29.0)$ & $62.9(66.4)$ \\
\hline $\mathrm{SBP}(\mathrm{mm} \mathrm{Hg})$ & $124.1(14.5)$ & $126.6(15.9)$ & $127.8(14.0)$ & $127.3(14.1)$ \\
\hline $\mathrm{DBP}(\mathrm{mm} \mathrm{Hg})$ & $78.3(10.1)$ & $80.6(10.7)$ & $81.6(9.5)$ & $81.4(9.6)$ \\
\hline
\end{tabular}

Data are expressed as the number (\%) of subjects or mean (SD).

ALT, alanine transaminase; AST, aspartate transaminase; DBP, diastolic blood pressure; FLD, fatty liver disease; GGT, gammaglutamyltransferase; HDL, high-density lipoprotein; SBP, systolic blood pressure. 


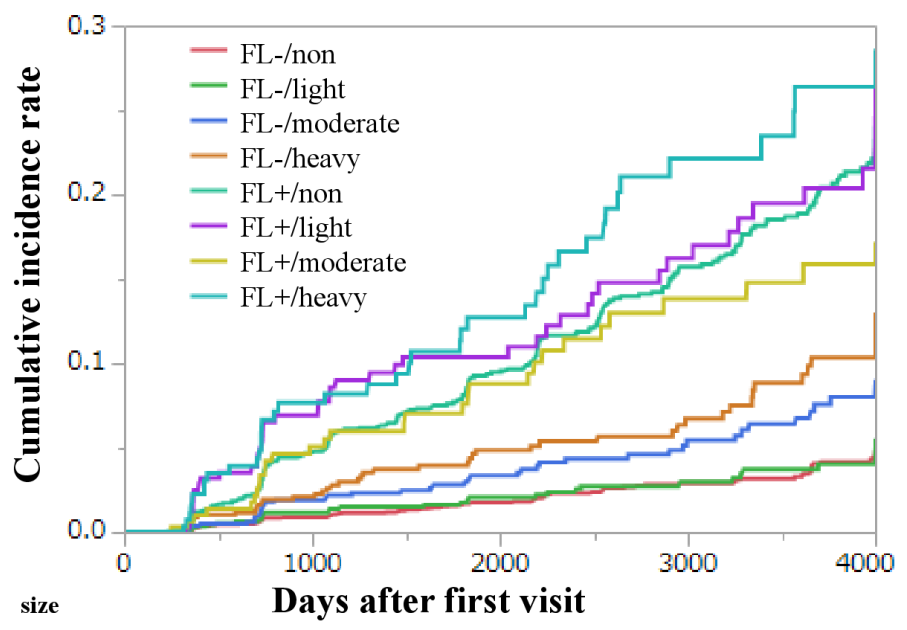

Sample size

Days after first visit

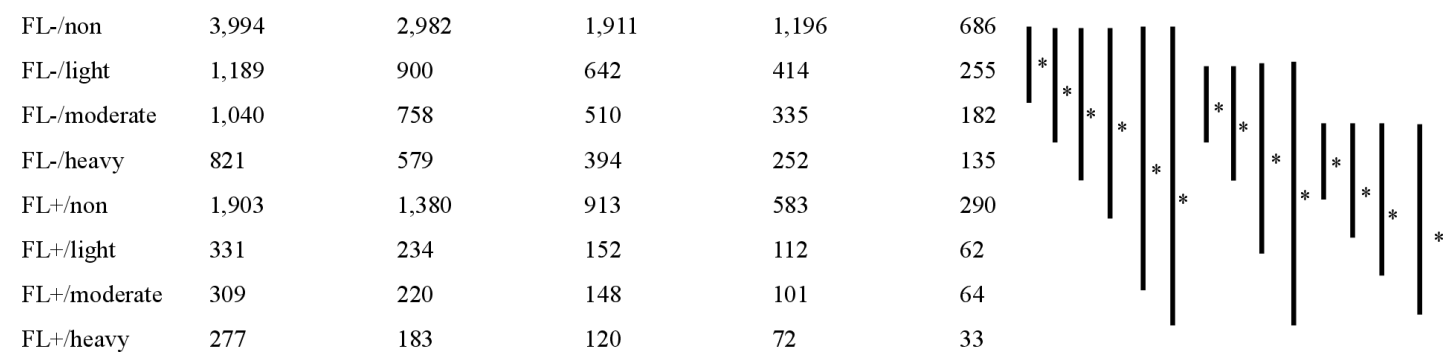

Figure 1 Kaplan-Meier analysis of incident chronic kidney disease (CKD) in 9948 men. Log-rank tests were used to determine the association among the eight groups according to the presence or absence of fatty liver disease (FLD) and grades of alcohol consumption. Bonferroni correction was performed to correct familiar error, and a $p$ value $<0.0018$ was considered significant. FL, fatty liver.

FLD showed a significantly lower risk for incident type 2 diabetes than the other groups. On the other hand, the none or minimal group with FLD and light alcohol consumers with FLD showed a significantly higher risk for incident type 2 diabetes, compared with the none or minimal group without FLD or light alcohol consumers without FLD. Heavy alcohol consumption with FLD showed a significantly higher risk when compared with the other groups, except for light alcohol consumption with FLD. Interestingly, moderate alcohol consumption without FLD had a significantly higher risk for incident type 2 diabetes, compared with the none or minimal group without FLD and light alcohol consumption without FLD (vs none or minimal, HR 1.76, 95\% CI 1.22 to $2.53, p=0.003$; vs light, HR $1.89,95 \%$ CI 1.20 to 2.99 , $\mathrm{p}=0.006$ ), whereas there was no apparent difference in the risk for incident type 2 diabetes between none or minimal, light, and moderate alcohol consumption with FLD (vs none or minimal, HR 0.87, 95\% CI 0.59 to 1.28 , $\mathrm{p}=0.480$; vs light, HR $0.71,95 \%$ CI 0.45 to $1.14, \mathrm{p}=0.151$ ). Furthermore, there was no statistically significant difference in the risk for incident type 2 diabetes between moderate and heavy alcohol consumption without FLD and none or minimal, light, and moderate alcohol consumption with FLD. Additionally, when the participants were divided into two categories according to the baseline year, the main findings were identical (online supplemental figure 2).

\section{DISCUSSION}

We investigated the risks for incident type 2 diabetes according to both the presence of FLD and the grades of alcohol consumption in a cohort of nearly 10000 Japanese for the mean 6.0-year follow-up. Here, we demonstrated that none or minimal and light alcohol consumption without FLD carried a lower risk for incident type 2 diabetes; however, even none or minimal and light alcohol consumers with FLD carried a higher risk for developing incident type 2 diabetes, compared with none or minimal and light alcohol consumers without FLD. The risk in moderate and heavy alcohol consumers even without FLD was higher, compared with that in none or minimal and light alcohol consumers without FLD. Moreover, we have revealed that the risk for incident type 2 diabetes in heavy alcohol consumers with FLD was highest among the eight groups.

Several previous animal studies and Western epidemiological studies reported that moderate alcohol consumption is protective for type 2 diabetes, that is, a J or U-shaped curve relationship, ${ }^{16-20}$ and there are several possible reasons. Previous studies revealed that moderate alcohol intake did not reduce the glucose-stimulated insulin secretion. ${ }^{21-23} \mathrm{In}$ addition, a relatively low dose of alcohol intake $(4 \mathrm{~g} / \mathrm{kg} /$ day) enhanced insulin signaling via increased binding of insulin receptor substrate 1 and phosphatidylinositol 3-kinase and subsequent activation of AKT, although a relatively high dose of alcohol intake 
Table 3 HRs of incident type 2 diabetes according to the groups

\begin{tabular}{|c|c|c|}
\hline & HR (95\% Cl) & $P$ value \\
\hline Age (years) & 1.03 (1.02 to 1.04$)$ & $<0.001$ \\
\hline $\begin{array}{l}\text { Body mass index } \\
\left(\mathrm{kg} / \mathrm{m}^{2}\right)\end{array}$ & 1.00 (0.94 to 1.04$)$ & 0.948 \\
\hline $\begin{array}{l}\text { Waist circumference } \\
\text { (cm) }\end{array}$ & $1.03(1.00$ to 1.05$)$ & 0.017 \\
\hline Never smoker & Reference & - \\
\hline Ex-smoker & 0.81 (0.64 to 1.01$)$ & 0.066 \\
\hline Current smoker & 1.26 (1.06 to 1.60$)$ & 0.013 \\
\hline Regular exerciser & 0.78 (0.60 to 0.99$)$ & 0.047 \\
\hline $\mathrm{HbA1c}(\mathrm{mmol} / \mathrm{L})$ & 1.35 (1.32 to 1.38$)$ & $<0.001$ \\
\hline Triglycerides (mmol/L) & 1.16 (1.07 to 1.26$)$ & $<0.001$ \\
\hline $\begin{array}{l}\text { Alanine transaminase } \\
\text { (IU/L) }\end{array}$ & 1.00 (1.00 to 1.01$)$ & 0.041 \\
\hline $\begin{array}{l}\text { Alcohol consumption } \\
\text { (g/week) }\end{array}$ & - & - \\
\hline $\begin{array}{l}\text { None or minimal alcohol } \\
\text { consumer }\end{array}$ & Reference & - \\
\hline Light alcohol consumer & 1.06 (0.82 to 1.36$)$ & 0.636 \\
\hline $\begin{array}{l}\text { Moderate alcohol } \\
\text { consumer }\end{array}$ & 1.23 (0.95 to 1.59$)$ & 0.121 \\
\hline Heavy alcohol consumer & 1.83 (1.43 to 2.33$)$ & $<0.001$ \\
\hline Fatty liver disease & 1.83 (1.49 to 2.26$)$ & $<0.001$ \\
\hline
\end{tabular}

This model was adjusted for age, body mass index, waist circumference, smoking status, exercise, $\mathrm{HbA1c}$, triglycerides, alanine transaminase grades of alcohol consumption, and fatty liver at baseline.

$\mathrm{HbA1c}$, hemoglobin A1c.

(13 g/kg/day) showed impairment of these insulin signaling pathways in a rat model. ${ }^{24}$ Moreover, Siler et al reported that moderate alcohol consumption modestly activates the hepatic de novo lipogenesis pathway, which converts excess carbohydrates into fatty acids. ${ }^{25}{ }^{26}$ Therefore, modest alcohol consumption may enhance glucose and lipid metabolisms, which suggests a protective effect on the development of type 2 diabetes.

On the other hand, a Japanese epidemiological study found a positive association between alcohol intake and insulin deficiency and insulin resistance. ${ }^{27}$ Moreover, Tsumura $e t a l^{28}$ showed that lean men with high ethanol consumption levels $(\geq 50.1 \mathrm{~mL} /$ day $)$ had an increased risk of type 2 diabetes. Watanabe et $a l^{29}$ also showed that alcohol consumption was a risk factor for diabetes development among Japanese men and women with a low BMI. The participants without FLD were significantly leaner than those with FLD. Comprehensively, it is possible that Japanese and Western individuals have different alcoholrelated risks of diabetes, based on their differences in the pathophysiology of type 2 diabetes; Japanese individuals are less obese and have greater $\beta$-cell dysfunction, whereas Western individuals have greater insulin resistance. ${ }^{30}$
Furthermore, another possible explanation for the difference in the effects of moderate alcohol between Japanese and Western is that Japanese are generally more likely to accumulate acetaldehyde. ${ }^{31}$ In our study, the participants with FLD were more obese than those without (FLD-: $\left.22.3 \mathrm{~kg} / \mathrm{m}^{2}, \mathrm{FLD}+: 25.7 \mathrm{~kg} / \mathrm{m}^{2}, \mathrm{p}<0.001\right)$. This suggests that the moderate alcohol consumer with FLD had the lowest incidence of diabetes among the participants with FLD because their ethanol metabolism might be similar to that of Westerners. Thus, moderate alcohol consumption had an impact on the incident diabetes not in the participants with FLD but in those without.

In addition, the presence of FLD is a relatively highrisk factor for incident type 2 diabetes. ${ }^{6}{ }^{32}$ FLD is caused by ectopic fat accumulation in the liver, ${ }^{33}$ which induces hyperglycemia, dyslipidemia, and subclinical inflammation, which would induce insulin resistance. ${ }^{34}$ Thus, heavy alcohol consumers with FLD are highest risk of incident type 2 diabetes.

The strengths of our study, the relatively large population-based longitudinal research, are that we diagnosed fatty liver using the same standardized diagnostic criteria $^{15}$ and adopted the standardized questionnaire for lifestyle factors. Our study also has some limitations. First, in this population, we diagnosed having FLD using ultrasonography. Compared with liver biopsy, ultrasonography may be inaccurate. However, ultrasonography has been shown to have high sensitivity and specificity in the diagnosis of fatty liver and has been found to be effective in the diagnosis of fatty liver. ${ }^{35}$ Second, the incident type 2 diabetes might have been underestimated because, for the diagnosis of diabetes, we did not perform an oral glucose tolerance test. Third, the ability to examine different levels of physical activity on glucose homeostasis and ectopic fat was limited. If we were able to evaluate the intensity and frequency of exercise, a more accurate analysis would be possible. Fourth, we did not distinguish diabetes into type 1 or type 2 diabetes; however, the incident type 1 diabetes in Japan is exceedingly low (approximately 2 cases /year/100 000 individuals) ${ }^{36}$ Fifth, because alcohol consumption of female participants was low, and the number of heavy alcohol consumers was especially low, we excluded female participants and focused on male participants in this study. Moreover, a previous study reported that alcohol consumption was less associated with the risk for type 2 diabetes, compared with several covariates such as BMI in women. ${ }^{34}$ Therefore, alcohol consumption in women is expected to be less associated with the risk for incident type 2 diabetes, compared with alcohol consumption in men. Lastly, we did not have the detail data of types of medication. If we had the data, subanalyses among the excluded participants might have yielded new insights.

In conclusion, the risk for incident type 2 diabetes in heavy alcohol consumers with FLD was the highest among the eight groups. Moreover, none or minimal and light alcohol consumers were associated with a low risk for incident type 2 diabetes in individuals without 


\begin{tabular}{|c|c|c|c|c|c|c|c|}
\hline $\begin{array}{c}\text { 1: FL-/non- } \\
91 / 3,994 \\
(2.3 \%)\end{array}$ & & & & & & & \\
\hline $\begin{array}{c}2 \text { vs. } 1 \\
0.93(0.62-1.40) \\
p=0.722\end{array}$ & $\begin{array}{l}\text { 2: FL-/light } \\
32 / 1,189 \\
(2.7 \%)\end{array}$ & & & & & & \\
\hline $\begin{array}{c}3 \text { vs. } 1 \\
1.76(1.22-2.53) \\
p=0.003\end{array}$ & $\begin{array}{c}3 \text { vs. } 2 \\
1.89(1.20-2.99) \\
p=0.006\end{array}$ & $\begin{array}{c}\text { 3: FL-/moderate } \\
44 / 1,040 \\
(4.2 \%)\end{array}$ & & & & & \\
\hline $\begin{array}{c}4 \text { vs. } 1 \\
2.04(1.42-2.93) \\
p<0.001\end{array}$ & $\begin{array}{c}4 \text { vs. } 2 \\
2.20(1.40-3.46) \\
p<0.001\end{array}$ & $\begin{array}{c}4 \text { vs. } 3 \\
1.16(0.77-1.75) \\
p=0.484\end{array}$ & $\begin{array}{c}\text { 4: FL-/ heavy } \\
47 / 821 \\
(5.7 \%)\end{array}$ & & & & \\
\hline $\begin{array}{c}5 \text { vs. } 1 \\
2.02(1.54-2.66) \\
p<0.001\end{array}$ & $\begin{array}{c}5 \text { vs. } 2 \\
2.18(1.48-3.21) \\
p<0.001\end{array}$ & $\begin{array}{c}5 \text { vs. } 3 \\
1.15(0.81-1.62) \\
p=0.425\end{array}$ & $\begin{array}{c}5 \text { vs. } 4 \\
0.99(0.71-1.38) \\
p=0.959\end{array}$ & $\begin{array}{c}\text { 5: FL+/non- } \\
231 / 1,903 \\
(12.1 \%)\end{array}$ & & & \\
\hline $\begin{array}{c}6 \text { vs. } 1 \\
2.47(1.68-3.62) \\
p<0.001\end{array}$ & $\begin{array}{c}6 \text { vs. } 2 \\
2.65(1.66-4.24) \\
p<0.001\end{array}$ & $\begin{array}{c}6 \text { vs. } 3 \\
1.40(0.91-2.16) \\
p=0.129\end{array}$ & $\begin{array}{c}6 \text { vs. } 4 \\
1.21(0.79-1.85) \\
p=0.384\end{array}$ & $\begin{array}{c}6 \text { vs. } 5 \\
1.22(0.88-1.68) \\
p=0.237\end{array}$ & $\begin{array}{c}\text { 6: } F L+/ l i g h t \\
47 / 331 \\
(14.2 \%)\end{array}$ & & \\
\hline $\begin{array}{c}7 \text { vs. } 1 \\
1.76(1.14-2.72) \\
p=0.014\end{array}$ & $\begin{array}{c}7 \text { vs. } 2 \\
1.90(1.14-3.16) \\
p=0.015\end{array}$ & $\begin{array}{c}7 \text { vs. } 3 \\
1.00(0.62-1.61) \\
p=0.995\end{array}$ & $\begin{array}{c}7 \text { vs. } 4 \\
0.86(0.54-1.38) \\
p=0.540\end{array}$ & $\begin{array}{c}7 \text { vs. } 5 \\
0.87(0.59-1.28) \\
p=0.480\end{array}$ & $\begin{array}{c}7 \text { vs. } 6 \\
0.71(0.45-1.14) \\
p=0.151\end{array}$ & $\begin{array}{c}\text { 7: FL+/moderate } \\
30 / 309 \\
(9.7 \%)\end{array}$ & \\
\hline $\begin{array}{c}8 \text { vs. } 1 \\
\text { 3. } 45(2.32-5.13) \\
p<0.001\end{array}$ & $\begin{array}{c}8 \text { vs. } 2 \\
3.71(2.30-6.00) \\
p<0.001\end{array}$ & $\begin{array}{c}8 \text { vs. } 3 \\
1.96(1.26-3.06) \\
p=0.003\end{array}$ & $\begin{array}{c}8 \text { vs. } 4 \\
1.69(1.10-2.61) \\
p=0.019\end{array}$ & $\begin{array}{c}8 \text { vs. } 5 \\
1.71(1.22-2.39) \\
p=0.004\end{array}$ & $\begin{array}{c}8 \text { vs. } 6 \\
1.40(0.92-2.14) \\
p=0.123\end{array}$ & $\begin{array}{c}8 \text { vs. } 7 \\
1.96(1.22-3.14) \\
p=0.005\end{array}$ & $\begin{array}{c}\text { 8: FL+/heavy } \\
41 / 277 \\
(14.8 \%)\end{array}$ \\
\hline
\end{tabular}

Figure $2 \mathrm{HRs}$ and 95\% Cls for incident type 2 diabetes in men. The numbers below each group indicate the number of participants who developed type 2 diabetes/participants classified in each group (percentage). The HRs and $95 \% \mathrm{Cls}$ were calculated adjusting for age, body mass index, waist circumference, smoking status, exercise, hemoglobin A1c, triglycerides and alanine transaminase at baseline. FL, fatty liver; non-, none or minimal.

FLD, but not in individuals with FLD. For the prevention of incident type 2 diabetes, clinicians have to focus on the presence of FLD and the patient's alcohol consumption.

Acknowledgements We thank all of the staff members in the medical health check-up center at Asahi University Hospital. We would like to thank Editage (www. editage.com) for English language editing.

Contributors TO contributed to the data research and analyses and wrote the manuscript. YH originated and designed the study, analyzed the data and reviewed the manuscript for intellectual content. $\mathrm{MH}$ contributed to the manuscript organization and reviewed and edited the manuscript. AO and TK originated the study, analyzed the data and contributed to the discussion. MF analyzed the data and reviewed and edited the manuscript. MH is the guarantor of this work and, as such, had full access to all of the data in the study and takes responsibility for the integrity of the data and the accuracy of the data analysis. All authors were involved in the writing of the manuscript and approved the manuscript's final version.

Funding The authors have not declared a specific grant for this research from any funding agency in the public, commercial or not-for-profit sectors.

Disclaimer The sponsors were not involved in the study design; in the collection, analysis, interpretation of data; in the writing of this manuscript; or in the decision to submit the article for publication.

Competing interests $\mathrm{YH}$ has received grants from Asahi Kasei Pharma, personal fees from Daiichi Sankyo, personal fees from Mitsubishi Tanabe Pharma, personal fees from Sanofi KK, personal fees from Novo Nordisk Pharma, outside the submitted work. MH has received grants from Asahi Kasei Pharma, Nippon Boehringer Ingelheim, Mitsubishi Tanabe Pharma, Daiichi Sankyo, Sanofi KK, Takeda Pharmaceutical, Astellas Pharma, Kyowa Kirin, Sumitomo Dainippon Pharma, Novo Nordisk Pharma, and Eli Lilly Japan KK, outside the submitted work. MF has received grants from Nippon Boehringer Ingelheim, Kissei Pharma, Mitsubishi Tanabe Pharma, Daiichi Sankyo, Sanofi KK, Takeda Pharma, Astellas Pharma, MSD KK, Kyowa Hakko Kirin, Sumitomo Dainippon Pharma, Kowa
Pharmaceutical, Novo Nordisk Pharma, Ono Pharma, Sanwa Kagaku Kenkyusho, Eli Lilly Japan KK, Taisho Pharma, Terumo, Teijin Pharma, Nippon Chemiphar, Johnson \& Johnson KK Medical, Abbott Japan, and received personal fees from Nippon Boehringer Ingelheim, Kissei Pharma, Mitsubishi Tanabe Pharma, Daiichi Sankyo, Sanofi KK, Takeda Pharma, Astellas Pharma, MSD KK, Kyowa Kirin, Sumitomo Dainippon Pharma, Kowa Pharma, Novo Nordisk Pharma, Ono Pharma, Sanwa Kagaku Kenkyusho, Eli Lilly Japan KK, Taisho Pharma, Bayer Yakuhin, AstraZeneca KK, Mochida Pharma, Abbott Japan, Medtronic Japan, Arkley, Teijin Pharma and Nipro, outside the submitted work.

Patient consent for publication Not required.

Ethics approval The study was approved by the Ethics Committee of Asahi University Hospital (IRB number: 2018-09-01), and written informed consent was obtained from each participant.

Provenance and peer review Not commissioned; externally peer reviewed.

Data availability statement Data are available upon reasonable request.

Open access This is an open access article distributed in accordance with the Creative Commons Attribution Non Commercial (CC BY-NC 4.0) license, which permits others to distribute, remix, adapt, build upon this work non-commercially, and license their derivative works on different terms, provided the original work is properly cited, appropriate credit is given, any changes made indicated, and the use is non-commercial. See: http://creativecommons.org/licenses/by-nc/4.0/.

\section{ORCID iDs}

Takuro Okamura http://orcid.org/0000-0001-7269-1697

Yoshitaka Hashimoto http://orcid.org/0000-0002-8794-0550

Masahide Hamaguchi http://orcid.org/0000-0002-8651-4445

\section{REFERENCES}

1 Goto Y. Epidemiological problems in diabetes mellitus. Tohoku J Exp Med 1983;141 Suppl:1-19.

2 Ministry of Health, Labour and Welfare. Survey of diabetes. Available: https://www.mhlw.go.jp/bunya/kenkou/kenkou_eiyou_ chousa.html [Accessed 3 July 2020]. 
3 NCD Risk Factor Collaboration (NCD-RisC). Worldwide trends in diabetes since 1980: a pooled analysis of 751 population-based studies with 4.4 million participants. Lancet 2016;387:1513-30.

4 Britton KA, Fox CS. Ectopic fat depots and cardiovascular disease. Circulation 2011;124:e837-41.

5 Byrne CD, Targher G, Fat E. Ectopic fat, insulin resistance, and nonalcoholic fatty liver disease: implications for cardiovascular disease. Arterioscler Thromb Vasc Biol 2014;34:1155-61.

6 Okamura T, Hashimoto Y, Hamaguchi M, et al. Ectopic fat obesity presents the greatest risk for incident type 2 diabetes: a population-based longitudinal study. Int J Obes 2019;43:139-48.

7 Li X-H, Yu F-F, Zhou Y-H, et al. Association between alcohol consumption and the risk of incident type 2 diabetes: a systematic review and dose-response meta-analysis. Am J Clin Nutr 2016;103:818-29.

8 Baliunas DO, Taylor BJ, Irving $\mathrm{H}$, et al. Alcohol as a risk factor for type 2 diabetes: a systematic review and meta-analysis. Diabetes Care 2009;32:2123-32.

9 Hashimoto Y, Hamaguchi M, Kojima T, et al. Modest alcohol consumption reduces the incidence of fatty liver in men: a population-based large-scale cohort study. J Gastroenterol Hepatol 2015;30:546-52.

10 Cao G, Yi T, Liu Q, et al. Alcohol consumption and risk of fatty liver disease: a meta-analysis. PeerJ 2016;4:e2633.

11 Moriya A, Iwasaki Y, Ohguchi S, et al. Roles of alcohol consumption in fatty liver: a longitudinal study. J Hepatol 2015;62:921-7.

12 Xu L, Xie J, Chen S, et al. Light-to-Moderate alcohol consumption is associated with increased risk of type 2 diabetes in individuals with nonalcoholic fatty liver disease: a nine-year cohort study. Am J Gastroenterol 2020;115:876-84.

13 Ryu S, Chang Y, Kim D-I, et al. Gamma-Glutamyltransferase as a predictor of chronic kidney disease in nonhypertensive and nondiabetic Korean men. Clin Chem 2007:53:71-7.

14 American Diabetes Association. Standards of medical care in diabetes--2011. Diabetes Care 2011;34 Suppl 1:S11-61.

15 Hamaguchi M, Kojima T, Itoh Y, et al. The severity of ultrasonographic findings in nonalcoholic fatty liver disease reflects the metabolic syndrome and visceral fat accumulation. $\mathrm{Am} \mathrm{J}$ Gastroenterol 2007;102:2708-15.

16 Klatsky AL. Alcohol, cardiovascular diseases and diabetes mellitus. Pharmacol Res 2007;55:237-47.

17 Howard AA, Arnsten JH, Gourevitch MN. Effect of alcohol consumption on diabetes mellitus: a systematic review. Ann Intern Med 2004:140:211-9.

18 Zilkens RR, Puddey IB. Alcohol and cardiovascular disease--more than one paradox to consider. Alcohol and type 2 diabetes--another paradox? J Cardiovasc Risk 2003;10:25-30.

19 Conigrave KM, Rimm EB. Alcohol for the prevention of type 2 diabetes mellitus? Treat Endocrinol 2003;2:145-52.

20 Hong J, Smith RR, Harvey AE, et al. Alcohol consumption promotes insulin sensitivity without affecting body fat levels. Int $J$ Obes 2009;33:197-203.
21 Shah JH, Wongsurawat N, Aran PP. Effect of ethanol on stimulusinduced insulin secretion and glucose tolerance. A study of mechanisms. Diabetes 1977;26:271-7.

22 Beulens JWJ, de Zoete EC, Kok FJ, et al. Effect of moderate alcohol consumption on adipokines and insulin sensitivity in lean and overweight men: a diet intervention study. Eur J Clin Nutr 2008;62:1098-105

23 Cordain L, Melby CL, Hamamoto AE, et al. Influence of moderate chronic wine consumption on insulin sensitivity and other correlates of syndrome $\mathrm{X}$ in moderately obese women. Metabolism 2000;49:1473-8.

24 He L, Marecki JC, Serrero G, et al. Dose-Dependent effects of alcohol on insulin signaling: partial explanation for biphasic alcohol impact on human health. Mol Endocrinol 2007;21:2541-50.

25 Siler SQ, Neese RA, Hellerstein MK. De novo lipogenesis, lipid kinetics, and whole-body lipid balances in humans after acute alcohol consumption. Am J Clin Nutr 1999;70:928-36.

26 Ameer F, Scandiuzzi L, Hasnain S, et al. De novo lipogenesis in health and disease. Metabolism 2014;63:895-902.

27 Ueda N, Yamamoto M, Nakamura M, et al. Alcohol-induced impaired insulin secretion in a Japanese population: 5-year follow up in the Gifu diabetes study. J Diabetes Investig 2020;3. doi:10.1111/ jdi.13260. [Epub ahead of print: 29 Mar 2020].

28 Tsumura K, Hayashi T, Suematsu C, et al. Daily alcohol consumption and the risk of type 2 diabetes in Japanese men: the Osaka health survey. Diabetes Care 1999;22:1432-7.

29 Watanabe M, Barzi F, Neal B, et al. Alcohol consumption and the risk of diabetes by body mass index levels in a cohort of 5,636 Japanese. Diabetes Res Clin Pract 2002;57:191-7.

30 Yabe D, Seino Y, Fukushima $M$, et al. $\beta$ cell dysfunction versus insulin resistance in the pathogenesis of type 2 diabetes in East Asians. Curr Diab Rep 2015;15:602.

31 Matsuo K, Wakai K, Hirose K, et al. Alcohol dehydrogenase 2 His47Arg polymorphism influences drinking habit independently of aldehyde dehydrogenase 2 Glu487Lys polymorphism: analysis of 2,299 Japanese subjects. Cancer Epidemiol Biomarkers Prev 2006;15:1009-13.

32 Fukuda T, Hamaguchi M, Kojima T, et al. The impact of non-alcoholic fatty liver disease on incident type 2 diabetes mellitus in nonoverweight individuals. Liver Int 2016;36:275-83.

33 Byrne CD. Ectopic fat, insulin resistance and non-alcoholic fatty liver disease. Proc Nutr Soc 2013;72:412-9.

34 Hashimoto Y, Hamaguchi M, Fukuda T, et al. BMI history and risk of incident fatty liver: a population-based large-scale cohort study. Eur J Gastroenterol Hepatol 2016;28:1188-93.

35 Hernaez R, Lazo M, Bonekamp S, et al. Diagnostic accuracy and reliability of ultrasonography for the detection of fatty liver: a metaanalysis. Hepatology 2011;54:1082-90.

36 Neville SE, Boye KS, Montgomery WS, et al. Diabetes in Japan: a review of disease burden and approaches to treatment. Diabetes Metab Res Rev 2009;25:705-16. 